\title{
Expression and mutation analysis of Cyclin A and Ki-67 in glioma and their correlation with tumor progression
}

\author{
CHENG MIAO $^{1}$, ZHIYONG WANG ${ }^{2}$, JING YANG $^{3}$, JING LI $^{1}$ and XUNZHAO GAO ${ }^{1}$ \\ ${ }^{1}$ Department of Neurology, Xinxiang Central Hospital, Xinxiang, Henan 453000; ${ }^{2}$ Department of Anatomy, \\ Xinxiang Medical University, Xinxiang, Henan 453003; ${ }^{3}$ Department of Neurology, \\ The First Affiliated Hospital of Zhengzhou University, Zhengzhou, Henan 450052, P.R. China
}

Received September 24, 2014; Accepted June 16, 2015

DOI: $10.3892 / \mathrm{ol} .2015 .3474$

\begin{abstract}
The present study aimed to analyze the expression and mutation of Cyclin A and Ki-67 in gliomas, and determine their correlation with tumor progression. Tissue samples of 186 diagnosed glioma patients were examined immunohistochemically for Cyclin A and Ki-67 expression. Gene mutation analysis was performed on genomic DNA extracted from patient samples, using polymerase chain reaction amplification and sequencing. Cyclin $\mathrm{A}$ and $\mathrm{Ki}-67$ expression were observed in the glioma and lymphatic metastasis tissues, and were analyzed using SPSS 14.0 statistical software. Of the total patients, 64 (34.41\%) were Cyclin A-positive and 68 (36.56\%) were Ki-67-positive. The expression of Cyclin A and Ki-67 in glioma was positively correlated with lymphatic metastasis. Statistically significant differences were observed in the mutation rate of Ki-67 $(\mathrm{P}<0.05)$, but not Cyclin $\mathrm{A}(\mathrm{P}>0.05)$, between the gliomas and metastatic tumors. In conclusion, Cyclin A and Ki-67 are highly expressed in glioma tissues, and their expression and mutation are associated with the lymphatic metastasis of glioma in the brain. It may be concluded that Cyclin A and $\mathrm{Ki}-67$ may be used as biomarkers to guide the diagnosis of glioma and evaluate the prognosis of affected patients.
\end{abstract}

\section{Introduction}

Gliomas are tumors that originate within brain tissues; they arise from glial cells and are the most common brain tumors, making up $45 \%$ of all tumors found in the brain (1). According to the data from the World Health Organization (WHO), glioblastoma is the second leading cause of cancer-related mortality in children and young adults below the age of 35 (2).

The early detection and diagnosis of gliomas has been improved significantly in recent years. However, the survival

Correspondence to: Dr Cheng Miao, Department of Neurology, Xinxiang Central Hospital, 56 Jinsui Road, Xinxiang, Henan 453000, P.R. China

E-mail: chengmiaocn@126.com

Key words: glioma, Cyclin A, Ki-67, lymphatic metastasis rate of patients with gliomas remains low. An urgent requirement therefore exists to understand the molecular mechanisms that underlie the occurrence and progression of gliomas and develop novel methods for the diagnosis and treatment of this type of brain tumor. In the majority of cases, the diagnosis of glioma at an early stage relies on the combination of clinical observation, imaging and pathological examination (3). In addition, cancer biomarkers hold promise for use in early tumor detection and diagnosis. Cyclin A and Ki-67 are highly expressed in several malignant tumors. Recently, their expression has been used as a powerful index for malignant cell proliferation and prognosis, but their roles in gliomas and their metastasis have remained poorly understood $(4,5)$.

In the present study, the expression and mutation of Cyclin $\mathrm{A}$ and $\mathrm{Ki}-67$ were detected in glioma tissues from patients, and their association with glioma classification and lymphatic metastasis was investigated. The results may provide useful information on the diagnosis, evaluation, treatment and prognosis of glioma patients.

\section{Materials and methods}

Glioma tissues. Specimens of brain tumors were obtained from glioma patients who received surgery between March 2009 and January 2014 in Xinxiang Central Hospital (Xinxiang, Henan, China). The degree of differentiation, infiltration levels, lymphatic metastasis and degree of malignancy were recorded for each patient. A total of 186 patients were included in the study. Of these patients, 107 were male and 79 were female, with ages ranging from 27 to 76 years old (mean, $48.92 \pm 8.29$ years). According to the $1999 \mathrm{WHO}$ classification system (6), the patients were divided into the following categories: 47 cases of astrocytic tumors, 21 cases of oligodendrogliomas, 19 cases of ependymoma, 26 cases of mixed gliomas, 15 cases of choroid plexus tumors, 17 cases of mixed neuronal-glial tumors, 26 cases of pineal parenchymal tumors, 9 cases of embryonal tumors and 6 cases of neuroblastomas. According to the $2000 \mathrm{WHO}$ grading system (7), which categorizes gliomas into low-grade glioma (WHO grade I-II) and high-grade glioma (WHO grade III-IV) (8), out of the 186 patients, 84 were grade I-II and 102 were grade III-IV. This study was conducted in accordance with the declaration of Helsinki. This study was conducted with approval from 

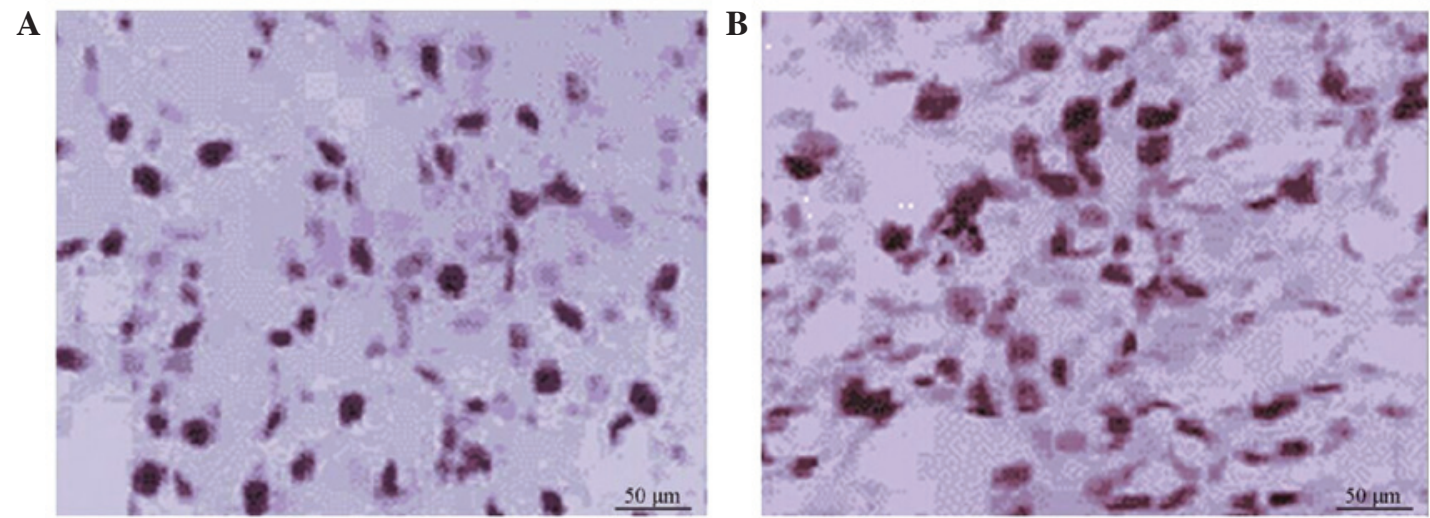

Figure 1. Immnostaining showing expression of Cyclin A and Ki-67 in glioma. (A) Positive expression of Cyclin A (magnification, x200). (B) Positive expression of Ki-67 (magnification, x200).

the Ethics Committee of Xinxiang Central Hospital. Written informed consent was obtained from all participants.

Immunohistochemistry. Paraffin blocks of surgical specimen from glioma patients were sectioned into $4-\mu \mathrm{m}$ slices, deparaffinized and rehydrated. The slides were washed with phosphate-buffered saline, treated with antibody signal enhancer, and incubated with mouse anti-human monoclonal antibody against Cyclin A (1:500; cat. no. LBP-IHC-M057) and mouse anti-human monoclonal antibody against Ki-67 (1:500; cat. no. LBP-IHC-R098) (both Daan Gene Inc., Guangzhou, China). Immunosignals were developed with DAB (Daan Gene Inc.) as the chromogen. The sections were contrast-stained with hematoxylin and mounted in neutral resin.

DNA extraction, polymerase chain reaction $(P C R)$ and sequencing. Fresh tissue samples $(30 \mathrm{mg})$ from glioma specimens or metastatic lymph nodes were homogenized with MagNA Lyser (Roche, Basel, Switzerland). The concentration of extracted genomic DNA was measured using NanoDrop 2000 (Thermo Scientific, Rockford, IL, USA), and the genomic DNA was diluted to a working concentration of 30-50 ng/l.

Four exons of Cyclin A and two codons of KRAS were amplified by PCR. Each reaction (in a total of $20 \mu \mathrm{l}$ reaction

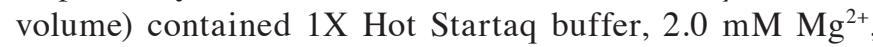
$0.2 \mathrm{mM}$ dNTP, $0.2 \mu \mathrm{M}$ of each primer, 1 unit of Hot Startaq polymerase and $10 \mathrm{ng}$ DNA template. PCR conditions were as follows: $95^{\circ} \mathrm{C}$ for $5 \mathrm{~min}$, followed by 25 cycles of $94^{\circ} \mathrm{C}$ for $40 \mathrm{sec}, 56^{\circ} \mathrm{C}$ for $30 \mathrm{sec}$ and $72^{\circ} \mathrm{C}$ for $40 \mathrm{sec}$ and final elongation at $72^{\circ} \mathrm{C}$ for $3 \mathrm{~min}$. The product was purified and sequenced using an ABI 3130XL Genetic Analyzer (Applied Biosystems, Foster City, CA, USA). The sequencing results were analyzed using PolyPhred analysis software (http://droog.gs.washington. edu/polyphred/real_polymorphism.html).

Detection of gene mutations. The mutations in Cyclin A and Ki-67 were detected using Cyclin A and Ki-67 Mutation Detection kits from Daan Gene Inc. Light Cycler 480 II (Roche) was used to detect the changes in the EGFR4 and KRAS genes.

Criteria and standards for immunohistochemistry. The positive signal was localized to the cytoplasm and membrane for Cyclin A staining, and to the membrane or cytoplasmic puncta for Ki-67 staining. The intensity of staining was evaluated in 10 areas of each section. The percentage of cells with positive staining was scored as follows: $0,<5 \%$ staining; 1, 6-25\% staining; 2, 26-50\% staining; 3, 51-75\% staining and $4,>75 \%$ staining. The staining intensity was scored as follows: 3 , brown; 2 , yellow; and 1, light yellow. The scores for percentage of positive cells and staining intensity were combined to generate an overall score index: Strongly positive $(+++), 6-9$ points; moderately positive $(++), 4-5$ points; weakly positive (+), 2-3 points; and negative (-), 0-1 points (9).

Statistical analysis. Statistical analysis was performed using SPSS 14.0 software (SPSS Inc., Chicago, IL, USA). The t-test was used to compare the difference between two groups. $\mathrm{P}<0.05$ was used to indicate a statistically significant difference.

\section{Results}

Expression of Cyclin A and Ki-67 in glioma. Out of 186 patients, 64 (34.41\%) were positive for Cyclin A staining and $68(36.56 \%)$ for Ki-67 staining in the glioma tissues or metastatic lymph nodes. Statistical analysis showed that the expression of Cyclin A and Ki-67 exhibited no correlation with the clinicopathological factors of age, gender, tumor size and smoking history $(\mathrm{P}>0.05)$ (Table I), but was correlated with the clinical stage, degree of differentiation and lymphatic metastasis. In the patients with poorly-differentiated tumors, lymphatic metastasis or grade III-IV gliomas, the positive expression rates for Cyclin A were 42.22, 47.25 and 47.12\%, respectively, and for $\mathrm{Ki}-67$, these rates were 41.48, 45.05 and $48.08 \%$, respectively (Table I). The positive rate for Cyclin A and $\mathrm{Ki}-67$ in these patients was significantly higher than that in patients with well-differentiated tumors, no lymphatic metastasis or grade I-II gliomas $(\mathrm{P}<0.05)$ (Table I; Fig. 1).

Mutation analysis of Ki-67 and Cyclin A genes in glioma tissues and metastatic lymph nodes. Of the 186 patients, 91 presented with lymphatic metastasis. In the 95 patients without lymphatic metastasis, 27 were found to have Ki-67 expression. In the 91 patients with lymphatic metastasis, 
Table I. Association between Cyclin A and Ki-67 expression and gliomas (mean \pm standard deviation).

\begin{tabular}{|c|c|c|c|c|c|c|c|c|c|}
\hline \multirow[b]{2}{*}{ Characteristic } & \multirow[b]{2}{*}{$\mathrm{n}$} & \multicolumn{2}{|c|}{$\begin{array}{c}\text { Cyclin A } \\
\text { expression, } \mathrm{n}\end{array}$} & \multirow{2}{*}{$\begin{array}{l}\text { Positive } \\
\text { rate, } \%\end{array}$} & \multirow[b]{2}{*}{ P-value } & \multicolumn{2}{|c|}{$\begin{array}{c}\text { Ki-67 } \\
\text { expression, } \mathrm{n}\end{array}$} & \multirow{2}{*}{$\begin{array}{c}\text { Positive } \\
\text { rate, } \%\end{array}$} & \multirow[b]{2}{*}{ P-value } \\
\hline & & $(-)$ & $(+)$ & & & $(-)$ & $(+)$ & & \\
\hline Patients & 186 & 122 & 64 & & & 118 & 68 & & \\
\hline Gender & & & & & 0.827 & & & & 0.952 \\
\hline Male & 107 & 69 & 38 & 35.51 & & 68 & 39 & 36.45 & \\
\hline Female & 79 & 53 & 26 & 32.91 & & 50 & 29 & 36.71 & \\
\hline Age, years & & & & & 0.762 & & & & 0.985 \\
\hline$<60$ & 123 & 79 & 44 & 35.77 & & 78 & 45 & 36.59 & \\
\hline$\geq 60$ & 63 & 43 & 20 & 31.75 & & 40 & 23 & 36.51 & \\
\hline Smoking history & & & & & 0.962 & & & & 0.809 \\
\hline Yes & 73 & 48 & 25 & 34.25 & & 45 & 28 & 38.36 & \\
\hline No & 113 & 74 & 39 & 34.51 & & 73 & 40 & 35.40 & \\
\hline Tumor size, $\mathrm{cm}$ & & & & & 0.274 & & & & 0.217 \\
\hline$\leq 4$ & 99 & 70 & 29 & 29.29 & & 69 & 30 & 30.30 & \\
\hline$>4$ & 87 & 52 & 35 & 40.23 & & 49 & 38 & 43.68 & \\
\hline TNM grading & & & & & $0.011^{\mathrm{a}}$ & & & & $0.024^{\mathrm{a}}$ \\
\hline I-II & 82 & 67 & 15 & 18.29 & & 64 & 18 & 21.95 & \\
\hline III-IV & 104 & 55 & 49 & 47.12 & & 54 & 50 & 48.08 & \\
\hline Differentiation & & & & & $0.003^{\mathrm{a}}$ & & & & $0.041^{\mathrm{a}}$ \\
\hline Well & 51 & 44 & 7 & 13.73 & & 39 & 12 & 23.53 & \\
\hline Poor & 135 & 78 & 57 & 42.22 & & 79 & 56 & 41.48 & \\
\hline Lymphatic metastasis & & & & & $0.028^{\mathrm{a}}$ & & & & $0.049^{\mathrm{a}}$ \\
\hline Yes & 91 & 48 & 43 & 47.25 & & 50 & 41 & 45.05 & \\
\hline No & 95 & 74 & 21 & 22.12 & & 68 & 27 & 28.42 & \\
\hline
\end{tabular}

${ }^{\mathrm{a}} \mathrm{P}<0.05$.

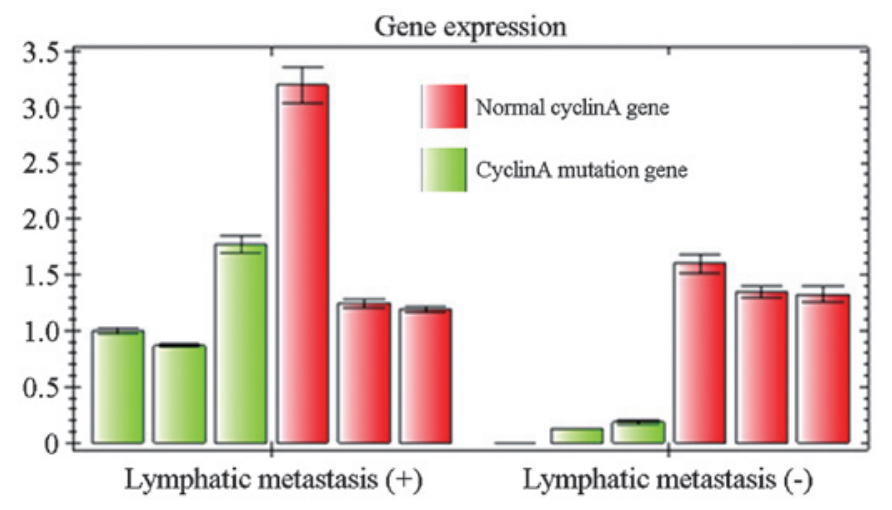

Figure 2. Relative expression of normal Cyclin A gene and Cyclin A mutation gene in patients with and without lymphatic metastasis.

34 were found to have $\mathrm{Ki}-67$ expression in the glioma tissues and 41 in the metastatic lymph nodes. There were significant differences in the mutation rate of $\mathrm{Ki}-67$ between the glioma and metastatic tissue sites $(\mathrm{P}<0.05)$. Point mutations of $\mathrm{Ki}-67$ were detected in 1 glioma tissue and 7 metastatic tissues. Of these mutations, 5 were mutated in the codon for amino acid 12 and 2 in the codon for amino acid 13. Statistical

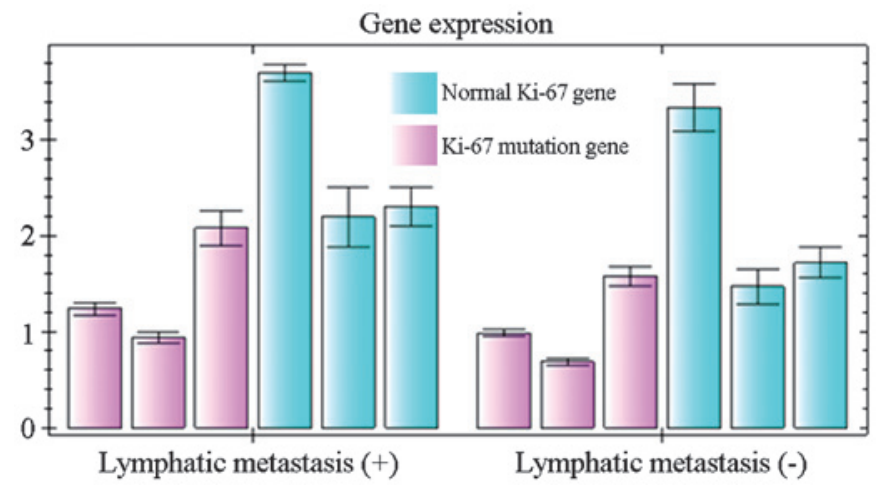

Figure 3. Mutations in Ki-67 gene. The relative expression of normal Ki-67 gene and $\mathrm{Ki}-67$ mutation gene in patients with and without lymphatic metastasis.

analysis showed that the $\mathrm{Ki}-67$ mutation rate was not associated with patient gender, smoking history and tumor subtype (Fig. 2).

With regard to Cyclin A, 21 of the patients without lymphatic metastasis were positive for its expression. In the patients with lymphatic metastasis, 32 were positive for Cyclin A expression in the glioma tissues and 43 in the metastatic tumor sites. Mutations in Cyclin A were identified in 21 
glioma tissues and 26 metastatic tumor tissues. There was no significant difference in the mutation rate of Cyclin A between the glioma tissues and the metastatic tissue sites $(\mathrm{P}>0.05)$. Statistical analysis showed that the mutation rate of Cyclin A in non-smoking women was significantly higher than that in men who smoked $(\mathrm{P}<0.05)$ (Fig. 3).

\section{Discussion}

Glioma is a primary brain tumor that originates from glial cells. The tumor has one of the worst prognoses. A better prognosis for glioma depends on its early detection and diagnosis. The rapid development of molecular biology and its application in cancer biology revolutionized the research on gliomas, and has generated significant insights into the mechanisms underlying glioma pathogenesis. Clinical observations suggest that the same gliomas diagnosed by conventional analysis of pathological features may have significant differences in their response to treatments and their prognosis, as well as in the invasion, recurrence and metastasis of these tumors $(10,11)$. Experimental data have shown that these differences are due to changes in genes, which necessitates the use of molecular biology and immunohistochemical techniques to detect gene or protein changes (12-14). In the present study, Ki-67 and Cyclin A, two important genes that are associated with malignant tumors, were selected and their expression and mutation in patients with gliomas was investigated.

Cyclin A belongs to the Cyclin family, a group of proteins that regulate the cell cycle. Cyclin A positively regulates the cell cycle. First identified in hepatitis B virus DNA integration sites in tumor cells of primary liver cancer, Cyclin A was believed to possess oncogenicity. Cyclin A is essential for cells to pass $\mathrm{S}$ phase and $\mathrm{G} 2 / \mathrm{M}$ phase. It accumulates in the late $\mathrm{G}_{1}$ phase prior to DNA synthesis, and participates in DNA replication, synthesis and the entry of cells into mitosis. Therefore, the expression level of Cyclin A is critical for the normal growth and proliferation of cells. Abnormal expression of Cyclin A may cause mismatch or incomplete synthesis of DNA, which is believed to lead to carcinogenesis. Cyclin A is highly expressed in several tumor cells, and has been used as an index of malignant proliferation of these cells and poor prognosis $(15,16)$. Ki-67 is a nuclear protein that is associated with cellular proliferation. Although it is necessary for mitosis, the exact mechanism is unknown. Positive expression of $\mathrm{Ki}-67$ indicates an active proliferation of cancer cells. In addition, $\mathrm{Ki}-67$ is also a protein that is associated with the cell cycle. Therefore, it is used as a biomarker for various malignant cancers. The expression of Ki-67 in poorly-differentiated tumor tissues is significantly higher than its expression in well-differentiated adenocarcinoma tissues, which indicates that the expression level of $\mathrm{Ki}-67$ is correlated with histological grading $(17,18)$. The present results suggest that the expression of $\mathrm{Ki}-67$ is associated with the occurrence and development of gliomas, and is a sign of poor prognosis.

The detection of mutations in $\mathrm{Ki}-67$ is important for the understanding of cancer progression and the development of proper therapeutic strategies. Mutations in Ki-67 occur at the early stages of tumorigenesis, and these mutations are similar in primary cancer and metastatic tissues. It has been hypothesized that the status of the KRAS genes will not be changed by therapies. Approximately $20 \%$ of gliomas have Ki-67 mutations. Gliomas are tumors with extreme heterogeneity. Therefore, the confirmation of the consistent expression of Cyclin A and Ki-67 in primary tumor sites and metastatic tumor sites is important for those who choose targeted cancer therapies (19).

Our results showed that the expression of Cyclin A was not correlated with gender, age, degree of invasion, tumor size, distant metastasis or clinical grading $(\mathrm{P}>0.05)$. However, it was associated with the degree of differentiation and lymphatic metastasis. The expression of Ki-67 was not correlated with gender, age, tumor size, distant metastasis and degree of differentiation $(\mathrm{P}>0.05)$, but was associated with the degree of invasion, lymphatic metastasis and clinical grading (Table I). These data suggest that the detection of Cyclin A and Ki-67 has clinical significance in determine the metastasis, progression and prognosis of glioma patients who receive surgery. In addition, these results showed that the genes of Cyclin A and Ki-67 can be changed during tumor metastasis, although the underlying mechanisms remain unknown. This phenomenon can explain the different responses of glioma patients to targeted therapies.

In clinical treatment, personalized and targeted therapies are becoming optimized choices for oncologists and patients. Adjuvant therapies have been used in the treatment of glioma patients prior to surgery. By reducing the size of tumors and lowing the grade of regional tumors, certain terminal cancer patients may obtain the opportunity for surgery. Examination of lymphatic metastasis can provide more accurate information for glioma grading, which will be useful for choosing the best treatment for the patients (20). Patients who are negative in conventional examination may have micrometastasis in the mediastinum, bone marrow and lungs. Such patients have reached grade IV, and should be treated with new adjuvant chemotherapy prior to any surgery. For glioma patients with metastasis in the bone marrow and peripheral blood, early chemotherapy should be administered prior to surgery, which has been shown to lower the grades of $35 \%$ of patients with grade III-IV gliomas (21). Certain studies have indicated that distant metastasis may occur in patients diagnosed with grade I gliomas. For such patients, the detection of biomarkers of tumors is necessary to identify metastasis and the requirement for chemotherapy prior to surgery (22).

In the present study, it was demonstrated that mutations in the Ki-67 and Cyclin A genes are not only important for tumorigenesis, but also promote invasion and metastasis. Thus, detecting the expression and mutation of Ki-67 and Cyclin A in primary tumor sites and metastatic lymph nodes may provide critical information for clinical diagnosis, disease evaluation, treatment and prognosis.

\section{References}

1. Scheidegger R, Wong ET and Alsop DC: Contributors to contrast between glioma and brain tissue in chemical exchange saturation transfer sensitive imaging at 3Tesla. Neuroimage 99: 256-268, 2014.

2. Stupp R, Hegi ME, Mason WP, van den Bent MJ, Taphoorn MJ, Janzer RC, Ludwin SK, Allgeier A, Fisher B, Belanger K, et al: Effects of radiotherapy with concomitant and adjuvant temozolomide versus radiotherapy alone on survival in glioblastoma in a randomised phase III study: 5-year analysis of the EORTC-NCIC trial. Lancet Oncol 10: 459-466, 2009. 
3. Sanai N, Chang S and Berger MS: Low-grade gliomas in adults. J Neurosurg 115: 948-965, 2011.

4. Tökés AM, Szász AM, Geszti F, et al: Expression of proliferation markers Ki67, cyclin A, geminin and aurora-kinase A in primary breast carcinomas and corresponding distant metastases. J Clin Pathol 68: 274-282, 2015.

5. Bosserhoff AK: Novel biomarkers in malignant melanoma. Clin Chim Acta 367: 28-35, 2006.

6. Kleihues P and Cavenee WK (eds): World Health Organization Classification of Tumours. Pathology and Genetics of Tumours of the Nervous System. IARC Press, Lyon, 2000.

7. Biernat W: 2000 World Health Organization classification of tumors of the nervous system. Pol J Pathol 51: 107-114, 2000.

8. Thomas L, Di Stefano AL and Ducray F: Predictive biomarkers in adult gliomas: The present and the future. Curr Opin Oncol 25 689-694, 2013.

9. Masuda TA, Inoue H, Sonoda H, Mine S, Yoshikawa Y Nakayama K, Nakayama K and Mori M: Clinical and biological significance of S-phase kinase-associated protein 2 (Skp2) gene expression in gastric carcinoma: Modulation of malignant phenotype by Skp2 overexpression, possibly via p27 proteolysis. Cancer Res 62: 3819-3825, 2002.

10. Katsetos CD, Reginato MJ, Baas PW, et al: Emerging microtubule targets in glioma therapy. Semin Pediatr Neurol 22: 49-72, 2015.

11. He X, Huang Q, Qiu X, et al: LAP3 promotes glioma progression by regulating proliferation, migration and invasion of glioma cells. Int J Biol Macromol 72: 1081-1089, 2015.

12. Takanami I: The prognostic value of overexpression of Skp2 mRNA in non-small cell lung cancer. Oncol Rep 13: 727-731, 2005.

13. Mason WP, Maestro RD, Eisenstat D, Forsyth P, Fulton D Laperrière $\mathrm{N}$, Macdonald $\mathrm{D}$, Perry $\mathrm{J}$ and Thiessen $\mathrm{B}$; Canadian GBM Recommendations Committee: Canadian recommendations for the treatment of glioblastoma multiforme. Curr Oncol 14 110-117, 2007.

14. Kamata Y, Watanabe J, Nishimura Y, Arai T, Kawaguchi M, Hattori M, Obokata A and Kuramoto H: High expression of skp2 correlates with poor prognosis in endometrial endometrioid adenocarcinoma. J Cancer Res Clin Oncol 131: 591-596, 2005.
15. Hart MG, Grant R, Garside R, Rogers G, Somerville M and Stein K: Temozolomide for high grade glioma. Cochrane Database Syst Rev 4: CD007415, 2008.

16. Mamillapalli R, Gavrilova N, Mihaylova VT, Tsvetkov LM, Wu H,Zhang $\mathrm{H}$ and Sun $\mathrm{H}$ : Pten regulates the ubiquitin-dependent degradation of the CDK inhibitor p27 (KIP1) through the ubiquitin E3 ligase SCF (SKP2). Curr Biol 11: 263-267, 2001.

17. von der Lehr N, Johansson S, Wu S, Bahram F, Castell A, Cetinkaya C, Hydbring P, Weidung I, Nakayama K, Nakayama KI, et al: The F-box protein Skp2 participates in c-Myc proteosomal degradation and acts as a cofactor for c-Myc-regulated transcription. Mol Cell 11: 1189-1200, 2003.

18. Hua W, Yao Y, Chu YW, et al: Phase I study of dendritic cells pulsed with tumor stem-like cells associated antigens against malignant glioma in recurrent patients. Zhong Hua Shen Jing Wai Ke Za Zhi 27: 90-94, 2011 (In Chinese).

19. Athanassiou H, Synodinou M, Maragoudakis E, Paraskevaidis M, Verigos C, Misailidou D, Antonadou D, Saris G, Beroukas K and Karageorgis P: Randomized phase II study of temozolomide and radiotherapy compared with radiotherapy alone in newly diagnosed glioblastoma multiforme. J Clin Oncol 23: 2372-2377, 2005.

20. Yang G, Ayala G, De Marzo A, Tian W, Frolov A, Wheeler TM, Thompson TC and Harper JW: Elevated Skp2 protein expression in human prostate cancer: Association with loss of the cyclin-dependent kinase inhibitor p27 and PTEN and with reduced recurrence-free survival. Clin Cancer Res 8: 3419-3426, 2002.

21. Dong Y, Sui L, Watanabe Y, Sugimoto K and Tokuda M: S-phase kinase-associated protein 2 expression in laryngeal squamous cell carcinomas and its prognostic implications. Oncol Rep 10: 321-325, 2003.

22. Stupp R, Mason WP, van den Bent MJ, Weller M, Fisher B, Taphoorn MJ, Belanger K, Brandes AA, Marosi C, Bogdahn U, et al: Radiotherapy plus concomitant and adjuvant temozolomide for glioblastoma. N Engl J Med 352: 987-996, 2005. 